Lepr Rev (2001) 72, 311-321

\title{
The experience of self-care groups with people affected by leprosy: ALERT, Ethiopia
}

\author{
CATHERINE BENBOW \& TEFERRA TAMIRU \\ ALERT, PO Box 165, Addis Adaba, Ethiopia
}

Accepted for publication 15 May 2001

\begin{abstract}
Summary This paper describes the development of self-care groups in Ethiopia by ALERT, and the successes and failures experienced in the process. The groups were started in 1995 in response to two main problems, the increasing number of people dependent on ALERT to heal their wounds despite years of health education, and the limited financial resources of ALERT for wound healing supplies. By December 1999, there were a total of 72 established groups. Group membership was voluntary. There have been a number of positive outcomes. Group members have taken up responsibility for managing and monitoring their own wounds and supplying their own wound healing materials. More attention is paid to their personal hygiene and personal appearance. They also report increased confidence to participate in society, retored dignity and self-respect, and a sense of belonging within the community. In addition, some members have started to pay more attention to their local environmental hygiene by building pit latrines and waste disposal sites. The ALERT staff involved in this initiative had to change their role from that of a leprosy service provider to a self-care group facilitator, but not all were successful in making this transition. The remaining challenge for the programme is sustainability and further development through the National Tuberculosis and Leprosy Control Programme, The Ethiopian National Association for Ex-Leprosy Patients and possibly other organizations too.
\end{abstract}

\section{Introduction}

This paper outlines the reasons that prompted the establishment of self-care groups, their development and the outcomes.

In 1995, ALERT staff expressed concern about the increasing number of people affected by leprosy who continued to use the ALERT hospital and field clinics for their wound management. In short, the traditional approach for the prevention and management of ulcers, the didactic, health education talk or lecture which might or might not include a practical demonstration of soaking, oiling, scraping, wound trimming and dressing, ${ }^{1}$ had disappointing results. The dressing of wounds was time consuming for the leprosy workers, who also expressed concern about the dependency of the people upon this service. There were limited

Correspondence to: Catherine Benbow, The Floors, Bourton, Much Wenlock, Shropshire, TF13 6QN, UK (e-mail: BenbowFloors@aol.com) 
financial resources available for wound healing materials, such as antiseptic, blades for trimming, Vaseline and bandages. These factors led ALERT staff to examine alternative methods of addressing the problems of wound management and the shortage of resources. It was decided to trial the use of self-care groups.

\section{Self-care groups}

The formation of a group of people is a natural phenomenon within society. The most effective groups have a specific aim, such as addressing a particular problem, bringing about change, or supporting one another. ${ }^{2}$ Group development is a dynamic process; some groups develop well and achieve results, whilst others remain fragmented or disband. Successful groups go through four stages: 'forming, storming, norming and performing' ${ }^{3}$ 'Forming' or starting is when a group of people come together with an apparently common objective. 'Storming' or conflict takes place when individuals within the group begin to express their previously unspoken reasons or agendas for joining the group and try to move the group in the direction they choose. It is essential that the objective of the group is clarified and individuals either agree to the objective or leave the group. 'Norming' or sorting out occurs when conflicts between individuals are resolved and the group starts to identify itself as a single unit, working towards the agreed objective. Finally, 'performing' or producing takes place when the group starts to achieve the objective. Some groups reach the 'producing' stage quickly, whilst others vacillate between the 'storming' and 'norming' stages, due to various agendas people bring and which can only be dealt with over time. Most groups that fail do so in the 'storming' stage. It is important that facilitators or groups understand these stages in order to respond appropriately.

The management of impairment, regardless of the health condition, whether physiological or psychological, is a challenge to the person affected, the family and community as well as the service providers. For some, a health condition may also result in problems of activity limitation and participation restriction. ${ }^{4}$ To address some of these problems, people around the world with a similar health condition have formed local and international support groups, such as mental health groups, ${ }^{5}$ addiction related recovery groups, ${ }^{6}$ diabetes groups, ${ }^{7}$ spinal injury groups ${ }^{8}$ and cancer groups, ${ }^{9}$ to name but a few. However, there is no such documented evidence of similar support groups for people affected by leprosy, and in particular, groups that address problems related to wound prevention and management.

Self-care groups are a form of support group. The ALERT self-care group philosophy, in the context of people affected by leprosy, is based on the premise that wound healing is the responsibility of those directly affected and uses the group dynamics of encouragement and accountability to support one another in wound management and obtaining wound healing materials.

Thus ALERT set up three self-care groups in 1995 on a 6-month trial basis in a colony area near Shashemane, $250 \mathrm{~km}$ south west of Addis Adaba, where there was a shortage of wound healing materials and a tradition of dependency upon a local hospital and clinic services.

Guidelines for 'establishing self-care groups', 'facilitating and running self-care groups', and a 'self-care data form' were developed by the six staff members who worked in the leprosy control programme. 
There were three main stages in the establishment of a self-care group: an introductory meeting, screening of possible members, and finally the establishment of the group.

The introductory meeting with possible group members was to explain the philosophy of the self-care groups:

- Group membership was voluntary (only those who wished to take responsibility for their own wound management could volunteer).

- Wound healing materials had to be provided by the group members themselves (not by ALERT).

- Members were required to participate actively in problem solving discussions, to develop practical solutions for wound healing and prevention and to monitor each other's progress.

- Canvas shoes with microcellular rubber (MCR) insoles were available at a subsidized cost of $\$ 1.25$ US at the group meeting ${ }^{10}$ (this footwear was also available at the leprosy clinic for any person with plantar anaesthesia).

- There were no handouts in this programme, such as clothing, food or monetary gifts.

There was also an opportunity for those present to ask any questions.

Potential members were screened according to membership criteria: diagnosed as having leprosy (on treatment or released from treatment) with $10 \mathrm{~g}$ monofilament anaesthesia of one or more points on the hands or feet. ${ }^{11,12}$ Beggars were usually excluded from the groups but if a beggar demonstrated positive behaviour and wished to change the 'begging use' of wounds, then the group members and facilitator could consider his/her request. A list of members was made and based on discussion with the members they were allocated into groups.

The ideal size for a group meeting to maximize participation, was between 7 and 10 members. ${ }^{13}$ This number allowed everyone to speak, although the quieter people would say less. However, the size of the group varied according to the locality and needs of the people. For a meeting to take place, at least $50 \%$ of the members had to be present.

Once the membership of a group was established, the members chose a group leader. The leader was responsible for running and managing the group and reporting any problems encountered within the group to the facilitator. The group, along with the facilitator, decided on a meeting place at a group member's home that was convenient for the majority of the members, and a timetable of meetings.

Group meetings were held every 1 or 2 weeks as decided by the members, and the monthly meetings were attended by the facilitator. The meetings normally lasted between $1 \frac{1}{2}$ and $2 \mathrm{~h}$.

\section{GROUP MEETINGS}

Meetings normally followed a preset format. The group members, including the group leader and facilitator (when present), sat in a circle. The leader and facilitator were responsible for creating a group environment where everyone was respected and everyone felt free to participate in the discussion, expressing their opinions as well as their doubts or ignorance. The meeting began with an introductory welcome and an update on issues of importance and interest to the group. The facilitator or group leader would usually open the discussion in a culturally acceptable manner, followed by general questions about the weather, harvest, cattle and family for example. A discussion about each member's personal appearance and hygiene followed, with suggestions if necessary, for improvement. 
The meeting continued with the inspection of each group member's hands and feet. The group members took their turn to sit on a stool in the middle of the circle, where they showed their hands and feet for inspection to the other members. Following the inspection of the skin condition and wound status, questions and comments could be put forward by any of the group members. The group discussion was ideally dynamic, with adequate time for each person. If there were no questions or comments, the group leader or the facilitator would suggest points for discussion by asking open and probing questions. If on the other hand, the discussion was going round in circles, the facilitator or group leader summarized the main points and brought the discussion back on track. At the end of the discussion, the summary focused on the action and solutions to be taken by each member, and on the role of the members in supporting each other because the outcomes would be monitored at the next meeting.

If a solution was developed which was not considered appropriate by the facilitator or group leader, it was their responsibility to make sure the group had a correct understanding of the problem being discussed, and appropriate solutions were then developed. For example, rest and clean dressings could not manage the problem of osteomyelitis; instead the group member should be referred to the hospital for surgery.

At the end of the meeting, the facilitator or group leader would investigate the reason for any absentees, then close the meeting, thanking the members for their participation, interest and results.

The facilitator visited each group once every 4 weeks. At these meetings, the facilitator listened to the reports of previous meetings and addressed any problems, assisted the group leader with the facilitation of the meetings and brought footwear for the members to purchase. The self-care data form was also completed at this meeting. This form recorded the wound status data and the solutions developed for each group member during the first 6 months of group membership.

After the 6-month period, the group members decided whether to continue or not. If the members decided to continue their meetings, they could request the facilitator to attend, but he/ she would not continue to fill out the self-care data form, only the group membership register.

\section{MEMBERSHIP CANCELLATION}

Members could be asked to leave the group if they did not participate actively in the group discussion or implement the advice given, if they were dominant or aggressive, if they tried to divert the aim of the group for other purposes, or were absent without notifying the group for more than four successive meetings.

\section{TRAINING OF STAFF}

The staff who took up the task of self-care group facilitation worked in the ALERT leprosy control programme. There was no formal training for the staff when the programme started. However, the six staff involved in the initial trial developed the guidelines from which they worked and gave each other support and advice. This process in itself proved to be a form of 'on the job' training.

In 1996, it was decided that the programme should be expanded in other areas of the leprosy control programme, so a 4-day 'introduction to self-care' workshop was conducted for the staff. However, this introduction was not sufficient for many of them to establish well 
functioning groups; and in 1998, a 4-day course was developed and conducted by the authors on 'The principles of adult learning, the art of facilitation and the procedure for setting up and running a self-care group'. The content of the training was kept simple. It was based on the understanding that the group members already knew how to prevent and heal their wounds (they had received years of formal health education), and since membership was voluntary it was assumed they would be motivated to take their responsibility for wound management. Therefore, the challenge to the staff was to develop constructive group dynamics, so the members would agree to implement solutions to heal their wounds and monitor each other's progress. The basic skills required to develop effective groups were discussed and demonstrated. However, the proficiency of the facilitator to listen and ask appropriate questions would be acquired as they gained experience in running groups. Only those leprosy workers who were interested in setting up self-care groups were encouraged to do so. However, the facilitators who ran groups received a daily per diem for each visit made, in line with the leprosy control programme procedures for staff when they leave their duty station. This per diem was therefore an incentive for some to establish groups.

The biggest challenge faced by the facilitators was the 'storming' stage in the group development. This stage is characterized by intra-group conflict, when the purpose of the group is being challenged because the members' previously unspoken agendas for joining the groups are verbalized. These unspoken agendas included the expectation that if they attended the meetings, they would receive handouts from the programme: wound dressing materials, clothing, grants and assistance with house building, for example. These handouts were available in the past. It was essential, therefore, that the facilitator held fast to their understanding of the self-care group philosophy so that the group could work through this stage; otherwise, the facilitator would be undermined and dispirited and the group in turn would fail. The other main challenge was the self-perception of the leprosy worker. If they wished to maintain the role of service provider with the white coat status, they would never make the transition to facilitator.

Supervision by those responsible for the programme (a social worker, therapist or proficient supervisor/facilitator) was essential and included an assessment of the group development, the skills of the facilitator and the wound management status. Supervision times also allowed the facilitator to raise their own questions and problems, plus those of the group that they could not address. At different stages in the group development, the facilitator faced different challenges that had to be managed. Sometimes, the facilitator learned more easily by observing the supervisor facilitating the group from time to time. They could observe the techniques used to control dominant members or to encourage quiet ones, the development of the discussion with well-framed questions and the important skill of listening. Assistance was usually required with completing the self-care data form.

No formal training sessions were conducted for the group leaders. It was expected that they would learn by example, by watching and listening to the facilitator and supervisor as they conducted the meeting.

\section{Findings}

GROUP DEVELOPMENT

Following the initial trial of 6 months, the programme was not formally evaluated, but based on the observation of improved wound cleanliness, healing of some wounds, reduction in size 
of others, improved skin condition and the interest of the group members in continuing, plus the desire of others wishing to join groups, it was decided to expand the programme. By December 1999, there were 34 functioning groups in Shashemane, 14 groups in Wolkeite, four in Addis Adaba and 20 in other areas of the ALERT leprosy control programme area with a total membership of 728 .

The group sizes varied. In 'leprosy villages' and urban areas where there were many group members, groups of 8-15 were formed, whereas groups of 3-6 were formed in rural areas where the members could be widely scattered. In contrast, members of small groups in some areas opted to join together to form one larger group, with a maximum membership of 15-18 people. Some members chose to walk distances of up to $2 \mathrm{~h}$, evidence of their commitment to the group.

With the exception of four groups, all opted to meet at group members' homes. Two of the four groups chose to meet at health stations because of the high level of stigma associated with leprosy in those areas, whilst the other two groups met in the homes of people (not affected by leprosy) who offered them as a more convenient meeting place than any of the group members' homes.

Without exception, all groups met every 4 weeks. Of these, $10 \%$ did not meet more of ten, $80 \%$ met every 2 weeks, and $10 \%$ met weekly. Every 4 weeks, the groups were visited by the facilitator and by May 1999, 16 well established groups in Shashemane and four in Wolkeite only required visits every 8 weeks. This in turn allowed the facilitators more time to establish new groups.

Of the 96 groups that were formed since 1995, 72 continued to meet (not one took the option to stop meeting after the first 6 months). Nine groups amalgamated due to declining membership caused by death, members moving away and others losing interest to continue. Fifteen groups failed because they did not develop past the storming phase due to intra-group tensions and alternative agendas or due to the limited skills and/or commitment of the facilitators.

WOUND MANAGEMENT MATERIALS

As part of the self-care philosophy, group members had to provide their own materials for wound management and they have adopted innovative, low cost solutions.

At first, some of the group members were reluctant to use their materials. They believed that wounds would not heal without the white bandage (it emerged that some members believed that the white bandages were impregnated with special healing qualities), without antiseptics and with only their own limited skill and knowledge. Some members believed that their disease gave employment to the staff and it was their right to receive medical wound care. Following discussions on these subjects and examples of wound healing by some of the group members, the sceptics in time decided to take control of their own wound problems. Wounds were cleaned using the water available and soap (but soap is not essential). Wounds were covered with a piece of cloth, usually a piece of old clothing or a shawl. It was either tied in place or secured by wearing a sock (even if full of holes!). The cloth pieces were washed and reused. An alternative to cloth were the cellulose strips from the stem of the false banana leaf, which were sterile and moulded easily around the limb. These strips were up to $1 \mathrm{~m}$ long and torn to the desired width. A constant supply was available wherever the trees were grown in Ethiopia. At first, some of the members were reluctant to use these strips because they were considered to be a 'traditional' material, but 
following the wound healing results of others using false banana 'bandages' they changed their minds and began to use them.

The core from a maize corncob was an excellent scraping tool; it was easy to hold and not as abrasive or as hard as a stone. Instead of surgical blades for trimming ulcers, razor blades were used, usually with considerable proficiency. If someone was not able to use a blade due to hand or visual problems, a family member usually trimmed the wound and if this was not possible, a group member would help instead.

To seal water absorbed into the hands and feet after soaking, Vaseline was bought by some members whilst others went without; some bought cooking oil as a cheaper alternative. Sometimes group members contributed a few cents to buy oil that was then distributed between them.

On no occasion were group members supplied with wound healing materials from the ALERT facilitators. If a group member chose to go to the local hospital or clinic for wound dressing they would be questioned by the group members as to their reason for attendance. If their reason was considered invalid, the member would be given advice and support to help them take up their responsibility for their wound management.

WOUND MANAGEMENT RESULTS

The self-care data form was developed for monitoring the wound status of the group members, but the skill of some of the facilitators in completing the forms was variable. This problem could be overcome in future by more training. Nevertheless, the forms were found to be of value for routine supervision purposes that included the approximate changes in wound size, wound healing, skin condition and the occurrence of new wounds. It should be pointed out that this programme was not established on research protocols but as an operational programme to assess whether group members would assume responsibility for their own wound problems. As a result, it is not possible to present statistically reliable wound management results for this paper.

However, an informal follow-up was conducted in December 1999 in two distinct communities. The first was the former leprosy colony near Shashemane where the group members live in close proximity and most people are involved with agriculture. The other area was Wolkeite, where the group members live alongside the general population within a more sparsely populated area and most of the people are traders and farming is of less importance.

The authors conducted the follow-up with 173 group members, 126 in Shashemane and 47 in Wolkeite, who were present on the day that the authors attended group meetings according to the routine programme. The follow-up took place between 12 and 50 months after the intake. The follow-up data collection was more exact than that recorded on the selfcare data forms (at intake and at 6 months) because any break in the continuity of the dermis was recorded as a wound, with the result that the wound count was higher than if the original facilitators had collected it.

In Shashemane, the number of people with foot wounds at intake was 51, at 6 months 36, and at follow-up 42; and in Wolkeite the number with wounds at intake was 15, at 6 months 12 , and at follow-up 8. In Shashemane the total number of dorsal and plantar foot wounds reduced from 76 to 50 between intake and 6 months, but rose from 50 to 52 between 6 months and follow-up; and in Wolkeite the reduction was from 34 to 14 between intake and 6 months and from 14 to 11 between 6 months and follow-up. 
In Shashemane, the number of feet with one or more wounds at intake was 65,44 feet at 6 months and 46 at follow-up; and in Wolkeite, there were 20 feet with one or more wounds at intake, 13 feet at 6 months and 10 at follow-up.

In Shashemane, the number of feet with one or more wounds at intake was 65, 44 feet at 6 months and 46 at follow-up; and in Wolkeite, there were 20 feet with one or more wounds at intake, 13 feet at 6 months and 10 at follow-up.

It should be noted that the change in the number of people with wounds, the number of wounds or feet affected at intake, at 6 months or at follow-up does not refer to specific individuals, wounds or feet, but rather to the overall wound total because some wounds were healed and some new ones had developed. Without exception, all wounds that were present at intake were smaller at follow-up. Some of these wounds were impossible to heal completely due to the condition of the skin, the underlying soft tissues and the altered bony structure of the foot, in addition to the need to carry out activities of daily living.

Hand wound results were variable and appeared to be related to working and seasonal conditions rather than the skill of the group members to prevent them. Some hand wounds were healed quickly whilst others resulted in bone loss. Superficial hand wounds were not recorded on the self-care data forms (the facilitators said they would heal quickly and therefore was no need to record them!) and the accurate recording of bone loss was problematic for the facilitators, therefore hand wound data are not included in this paper.

At any one time, $90 \%$ of the total group membership had well hydrated skin, $85 \%$ had clean and well-trimmed wounds and $80 \%$ of the wounds were covered (superficial wounds were often left uncovered), and $95 \%$ wore footwear, which despite the various stages of wear, did afford varying degrees of protection.

Self-care groups were unable to stop their members getting wounds because of the very nature of the sensory and autonomic dysfunction and altered anatomy of the foot and hand. Rather, the most important function of the groups was to enable the group members to develop a positive attitude towards their responsibility in the wound management process. Some of the staff considered the attitude and behavioural change of the members more important than the specific quantitative wound healing results, given that wound occurrence is inevitable.

\section{FACILITATORS}

Some leprosy workers made the transition to facilitator easily, whilst others, even after training, remained as formal health educators and did not believe in the basic philosophy of the groups. Of the 53 leprosy workers in the control programme, 17 succeeded in establishing groups, eight started but failed and 28 did not start at all.

\section{Unexpected outcomes}

In addition to the expected benefits of the self-care groups, there were a number of unexpected outcomes.

Group members mentioned feelings of 'belonging to a group', improved self respect and dignity and confidence to participate socially. Others who required help with harvesting or house repairs received assistance from other group members and even their families. The following quotations from the group members illustrate these outcomes: 
- 'We participate in society now. For example, when we attend a coffee ceremony, we don't hide our hands and feet any more. Now we sit with outstretched feet, show our hands when eating and gesticulate when talking'.

- 'We don't go to the hospital or orthopaedic workshop for ulcer treatment any more. Why should we? We can do it ourselves'.

- 'Because we no longer smell and are surrounded by flies, my daughter married into a nonleprosy family'.

- 'Once we were dependent on the hospital and had wounds, now we are independent and we don't have wounds because we can heal them ourselves; now we have our dignity and self respect'.

- 'Sometimes we help one another with work, harvesting for example, so that members can rest. We are becoming like a family and share occasions together'.

The group members made important suggestions to develop the programme. One suggestion resulted in an increased selection of subsidized commercial footwear from ALERT. Additional styles of canvas shoes with MCR were introduced and PVC boots with MCR for use in the rainy season, all at a cost of $\$ 1.25$ US a pair to the group members. ${ }^{14}$ However, some members with shortened feet liked the PVC boots for cosmetic reasons, and those with drop feet wore the boots because they act as a drop foot splint. These boots were worn during the dry season too, but with no reported problems of heat burns or excess sweating that might cause wounds or prevent existing wounds from healing. A smart looking leather jogging shoe with MCR at a cost of \$5 US was also available.

Another suggestion resulted in a limited number of group members taking an increased interest in environmental hygiene, with the result that some have dug their own pit latrines and pay greater attention to the cleanliness of their compounds.

Other requests included the availability of family planning measures given the shortage of land to support their families, loans, technical input to improve their agriculture output and better access to eye care, which could be addressed in the future.

In the Wolkeite area, the group members introduced a system of fines to punish those who failed to implement the advice given, because the 'purpose of the group was being dishonoured as well as the other members'. Those fined usually paid a few cents, but on occasions as much as \$1 US would be agreed upon by the group. These same groups also introduced a series of claps, one two or three, to reward improvement and good wound prevention and healing.

The self-care programme also provided a useful structure used for carrying out a number of studies by staff and trainees at ALERT, such as 'Who is at risk of developing wounds and why?' and 'Tool handle shapes for those with upper limb motor paralysis'. Other studies were proposed, for example, a comparison of the quality of life between those affected by leprosy, those affected by leprosy who are group members, and the general population who live in the same area; and an investigation into the use of the group structure for the implementation of a loan scheme.

The self-care programme was established to address the problems of wound management but the groups have provided more than just wound management support to one another. Given the unexpected outcomes of the programme, some staff asked why the poeple affected by leprosy could not decide on the criteria for group membership. In the future group members and potential members should be asked what criteria they would recommend. 


\section{Costing}

Costing this initiative was difficult, since it was an integral part of the prevention of disability programme within the MDT programme. Each group was visited once every 4 weeks by the local area leprosy supervisor or facilitator for the first 6 months following the initial setting up stage, which required four to six visits. The transportation costs varied fom area to area; in Shashemane the costs were small as the groups were close together, but in Wolkeite they were much higher because the groups were up to $50 \mathrm{~km}$ from the duty station. In addition to the facilitator, a supervisor from ALERT headquarters would sometimes visit the groups but not all groups were supervised. Groups in distant, isolated areas were not supervised because of the time required and the costs involved.

It was estimated that the cost of establishing and running a group was approximately $\$ 20$ US per visit ( $\$ 220$ to set up and facilitate a group for 6 months). This costing was based on the facilitator's and driver's daily salary, their lunch allowance, fuel, maintenance, insurance and lubricants for the vehicle (excluding vehicle purchase and depreciation), for a $50 \mathrm{~km}$ round journey from the duty station. Supervisory visits by ALERT headquarter based staff cost more because of the distance from ALERT to the duty station and the overnight per diem.

In addition to the costs of the programme, there were savings in the use of hospital services for wound management. Although the reduction was not measured, the hospital at Shashemane which is the main leprosy referral hospital for the south of Ethiopia, reported a decline in the number of people attending for wound care after the self-care programme was started.

\section{Issues of sustainability}

This programme has succeeded in setting up a number of self-care groups for people affected by leprosy, however the programme needs to be expanded throughout Ethiopia. ALERT cannot undertake this task because all leprosy related activities have now been integrated within the National Tuberculosis and Leprosy Programme (NTBLP) who will continue to strengthen this programme.

Another option considered for the expansion of this programme was its integration within the Ethiopian National Association for Ex-Leprosy Patients (ENAELP). The self-care philosophy and development process could also be taken up by community development projects, working in conjunction with the NTBLP and ENAELP.

\section{Conclusions}

This paper reports on the self-care programme established by ALERT, as part of the MDT programme. The programme successfully established a number of self-care groups for people affected by leprosy. The main function of the groups was to encourage the members to take responsibility for wound management, which was achieved. The number of wounds reduced most notably during the first 6 months of joining a group but these results were maintained over time. The group members reported a number of qualitative benefits, in particular improved self-respect and dignity and increased participation in society. 
Seventy-two groups developed useful outcomes, nine groups amalgamated and 15 groups failed during the 'storming' stage of the group development. Of the 53 leprosy workers who received training in self-care groups, 17 succeeded and eight failed in establishing groups, and 28 were not able to make the transition from health service provider to facilitator or were not interested for personal or environmental reasons, such as working in areas of high stigma or with isolated people.

It was not possible to cost the initiative exactly, due to the integrated nature of the MDT programme, but it was estimated that the cost per group visit was approximately \$20 US. There were also some cost savings to the health service.

This initiative shows that it is possible to set up self-care groups, although some failure must be expected. The benefits to the individual members can be enormous, enabling them to manage their own wound problems, giving them a sense of control over their impairments, making other changes to their life style and environment and enabling them to participate more fully in society.

\section{Acknowledgements}

The authors wish to thank Dr P. Saunderson, Dr Mengistu Asnake and Dr Assefa Amenu for their support of this programme at different times during the last 5 years, and Miss Heather Currie, Head of Physiotherapy for her enthusiasm in supporting the programme during the early years. However, special thanks go to the leprosy workers who made the transition to facilitators and who developed successful groups but who are too many to mention by name. The self-care programme was funded by the Netherlands Leprosy Relief as part of the prevention of disability activities in the leprosy programme.

\section{References}

1 Watson, JM. Preventing disability in leprosy patients. The Leprosy Mission International, London, UK, 1988.

2 WHO. Education for health. A manual on health education in primary health care. World Health Organization, Geneva, 1988.

3 Handy C. Understanding organisations. Penguin Books, Harmondsworth, 1985.

4 WHO. ICIDH2, The international classification of impairments, functioning and disability, Beta-2 draft, full version. 1999. Available from URL: http://www.who.int/icidh/.

${ }^{5}$ Kurtz LF. Mutual aid for affective disorders: the Manic Depressive and Depression Association. Am $J$ Orthopsychiatr, 1988; 58: 152-155.

6 Tattersall ML, Hallstrom C. Self-help and benzodiazepine withdrawal. J Affect Disord, 1992; 24: $193-198$.

7 Gilden JL, Hendryx MS et al. Diabetes support groups improve health care of older diabetic patients. J Am Geriatr Soc, 1992; 40: 147-150.

${ }^{8}$ Stewart R, Bhagwanjee A. Prompting group empowerment and self reliance through participatory research: a case study of people with physical disability. Disabil Rehabil, 1999; 21: 338-345.

9 Maisiak R, Cain M et al. Evaluation of TOUCH: an oncology self-help group. Oncology Nursing Forum, 1981; 8: $20-25$.

10 Seboka G, Saunderson P. Cost effective footwear for leprosy control programmes: a study in rural Ethiopia. Lepr Rev, 1996; 67: 208-216.

11 Hammond CJ, Klenerman P. Protective sensation in the foot in leprosy. Lepr Rev, 1988; 59: 347-354.

12 Birke JA, Sims DS. Plantar sensory threshold in the ulcerative foot. Lepr Rev, 1986; 57: 261-267.

13 Rogers, J. Adults learning. Open University Press, Milton Keynes, 1989.

14 Seboka G, Saunderson P, Currie H. Footwear for farmers affected by leprosy. Lepr Rev, 1998; 68: $182-183$. 